\title{
Prevalence of Hyponatremia in cirrhotic patients with encephalopathy.
}

1. MBBS, FCPS (Gastro) Senior Registrar Gastroenterology Liaquat National Hospital, Karachi.

2. MBBS, FCPS (Gastro)

Counsultant Gastroenterology Indus Hospital, Karachi.

3. MBBS, FCPS (Gastro)

Consultant Gastroenterology Liari General Hospital, Karachi.

4. MBBS, FCPS (Gastro)

Senior Registrar Gastroenterology Liaquat National Hospital, Karachi.

5. MBBS

Registrar Gastroenterology

Liaquat National Hospital, Karachi.

6. MBBS

Registrar Gastroenterology

Indus Hospital, Karachi.

Correspondence Address:

Dr. Hamid Ali Kalwar

Department of Gastroenterology

Liaquat National Hospital, Karachi.

hakalwar.345@gmail.com

Article received on:

25/03/2020

Accepted for publication:

$21 / 11 / 2020$
Tauqeer Shaikh ${ }^{1}$, Hamid Ali Kalwar ${ }^{2}$, Ghulam Mujtaba ${ }^{3}$, Adeel Rahat ${ }^{4}$, Kamaran Ali $^{5}$, Muhammad Babar $^{6}$

ABSTRACT... Objective: To Determine the frequency of hyponatremia in cirrhotic patients with encephalopathy. Study Design: Cross Sectional Study. Setting: Department of Gastroenterology Liaquat National Hospital Karachi. Period: 6 Dec 2017 to 6 June 2018. Material \& Methods: All those fulfilling the inclusion criteria and admitted in the Gastroenterology department of Liaquat National Hospital Karachi were taken in the study after their ethical approval alongside an informed and written consent. Brief history was taken, clinical examination was done, and serum sodium level was delivered to the institutional laboratory to reach the outcome i-e hyponatremia. Results: - A number of 369 patients having encephalopathy were taken into study. 207 patients $(56.1 \%)$ were males and 162 patients $(43.9 \%)$ were females with an average age of $50.03+10.333$ years. Hyponatremia was seen in 138 patients $(37.4 \%)$. Conclusion: Dilutional hyponatremia is a common finding in liver cirrhosis patients with encephalopathy leading to neurological impairment, hepatorenal syndrome, osteoporosis and high mortality. Therefore, early management of hyponatremia is key to prevent liver cirrhosis related complications.

Key words: $\quad$ Encephalopathy, Hyponatremia, Liver Cirrhosis.

Article Citation: Shaikh T, Kalwar HA, Mujtaba G, Rahat A, Kamaran, Babar M. Prevalence of Hyponatremia in cirrhotic patients with encephalopathy. Professional Med J 2021; 28(9):1308-1314. https://doi.org/10.29309/TPMJ/2021.28.09.4676

\section{INTRODUCTION}

Cirrhosis of liver and its complication are the major health problem, due to the large number of cases of hepatitis $B$ and hepatitis $C$ in our community ${ }^{1}$ and it is the common reason of mortality among Pakistan population and frequent cause of admission to hospital in pakistan. ${ }^{2}$

In situation of decompensation, portal hypertension, patients with cirrhosis generally present with ascites, gastrointestinal hemorrhage, jaundice, spontaneous bacterial peritonitis (SBP) and the hepatic encephalopathy. ${ }^{3}$

The clinical path of chronic liver disease (CLD) patients is frequently complicated by the occurrence of renal function disorders and electrolyte imbalances. ${ }^{4} \mathrm{~A}$ disruption in body water homeostasis is a common feature of advance cirrhosis. This disruption is always linked with the presence of ascites and with the growth of dilutional hyponatremia, which is a common complication and consequence of chronic liver disease. ${ }^{5}$ Hepatic encephalopathy can be induced or aggravated by hyponatremia, resulting in disease progression and even death. ${ }^{5}$

Recent study indicates that hyponatremia is a key prognostic issue in patients with chronic liver disease (CLD). ${ }^{6}$ The occurrence of hyponatremia in patients of cirrhosis with ascites is nearly $30 \%{ }^{7}$

The association between cirrhosis severity and hyponatremia is associated with progression of complication, i.e. hepatic encephalopathy, hepatorenal syndrome, and spontaneous bacterial peritonitis, is greater in patients with serum sodium concentration $<130 \mathrm{mEq} / \mathrm{L}$ than those with higher levels. ${ }^{6}$

In addition, in patients with ascites, those with hyponatremia have a lower response to diuretics, an increased occurrence of refractory ascites, and a frequent need for therapeutic paracentesis. ${ }^{8}$ the aim of this study is to determine the frequency of hyponatremia in cirrhotic encephalopathic 
patients.

As above mentioned, studies show variations in result that is why we conducted this study in our population to observe the actual occurrence of hyponatremia in cirrhotic patients with encephalopathy.

This study will help the patients as well as health care provider by early identifying hyponatremia and its management will help in minimizing the complications associated with hyponatremia it will ultimately reduce the cost of health care and also morbidity and mortality rate in these cases.

\section{MATERIAL \&METHODS}

This cross-sectional study was conducted in Liaquat National Hospital Karachi's Department of Gastroenterology, from $6^{\text {th }}$ Dec 2017 till $6^{\text {th }}$ June 2018. This study was done after the consent of ethical committee of institute (APP.NO.04852019-LNK-ERC). Subjects were selected from the gastroenterology ward of Liaquat National Hospital, Karachi. All the patients satisfying the inclusion criteria were selected in the study. Written approval was taken from all the patients or their relatives. Comprehensive history, clinical inspection and various routine and required investigations were made in all subjects with usual aseptic measures $2 \mathrm{ml}$ blood sample was collected from cubital vein into $5 \mathrm{cc}$ disposable syringe for serum sodium estimation and was delivered to diagnostic and research laboratory for analyses. The frequency of hyponatremia was evaluated while the HE was graded according to the West Haven classification Grades I-II was taken as mild to moderate encephalopathy, while grades III-IV was taken as severe encephalopathy. The demographic profile of the patient was noted. The serum sodium $[\mathrm{Na}+]$ level $135-145 \mathrm{mmol} / \mathrm{L}$ was taken as normal and the value $<135$ was labeled as hyponatremia. The severity of hyponatremia was categorized as: mild, moderate and severe. All the data regarding gender, age, serum sodium level, grades and duration of hepatic encephalopathy was recorded on proforma attached.

\section{Statistical Analysis}

All the data was entered in SPSS 22.0 version and was examined by the same software. The quantitative data like age, duration of hepatic encephalopathy, serum sodium level was presented in form of mean \pm S.D. Simple frequency and percentage were computed for the gender, virology, child Pugh class (grade B/grade $\mathrm{C})$, grades of $\mathrm{HE}$ and hyponatremia. Stratification with respect to the gender, age, grades and duration of $\mathrm{HE}$ and viral markers, child Pugh class was done to control the effect modifiers. Chi-Square test was applied and P-value $<0.05$ was considered as significant.

\section{RESULTS}

A number of 369 patients with encephalopathy were selected to conduct this study with the mean age of $50.03+10.333$ years. The distribution of age is presented in Figure-1. The descriptive statistics of age is presented in Table-I.

207 patients (56.1\%) were males \& 162 (43.9\%) were females.

The mean duration of hepatic encephalopathy was $2.043+0.711$ days. The descriptive statistics of duration of hepatic encephalopathy is presented in Table-I.

The mean serum sodium level was $135.71+7.940$ $\mathrm{meq} / \mathrm{l}$. The descriptive statistics of serum sodium level is presented in Table-I.

In our study 89 patients (24.1\%) had HBV, 25 (6.8\%) had both HBV \& HDV, 244 (66.1\%) had $\mathrm{HCV}$ and $11(3 \%)$ had both HCV \& HBV, as shown in Table-l.

100 patients (27.1\%) were child B \& 269 (72.9\%) were child $\mathrm{C}$, as shown in Table-l.

Grades of hepatic encephalopathy were grade-I in 0 patients $(0 \%)$, grade-II in $151(41 \%)$, grade-III in $133(36 \%)$ \& grade- $\mathrm{VI}$ in $85(23 \%)$, as shown in Table-I.

In our study hyponatremia was seen in 138 patients (37.4\%). The distribution of hyponatremia 
is presented in Table-I.

The frequencies of age groups, gender, viral markers, Child-Pugh class, duration of hepatic encephalopathy, grades of hepatic encephalopathy were calculated according to hyponatremia. The results are presented in TableII and Table-III respectively.

In our study the hyponatremia is significantly associated with age, gender, viral markers, ChildPugh class, duration of hepatic encephalopathy \& grades of hepatic encephalopathy with the P-value of $0.001,0.038,0.001,0.001,0.001$ \& 0.001 respectively.

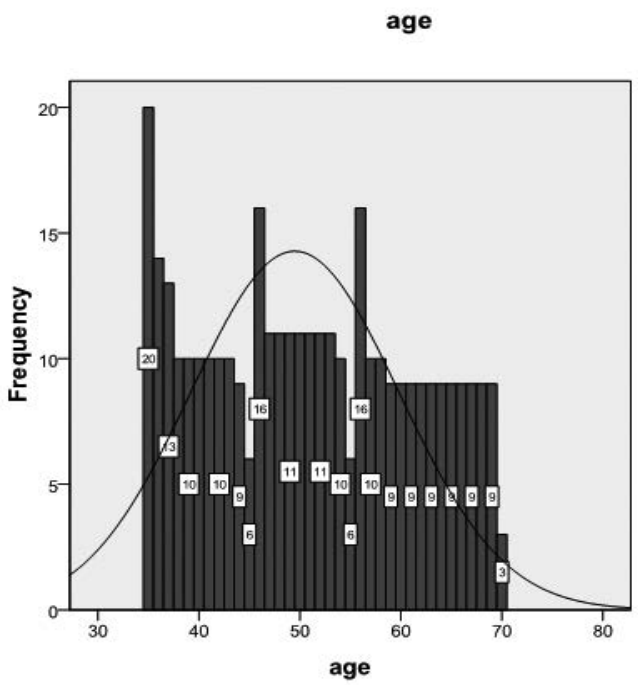

Figure-1. Frequency distribution of age (years).

\begin{tabular}{|l|c|}
\hline \multicolumn{1}{|c|}{ Variable } & Mean+SD \\
\hline Age & $50.03+10.333$ \\
\hline Duration of Hepatic Encephalopathy & $2.043+0.711$ \\
\hline Serum Sodium Level & $135.71+7.940$ \\
\hline Gender & Frequency (N) \\
\hline Male & $207(56.1 \%)$ \\
\hline Female & $162(43.9 \%)$ \\
\hline Total & $369(\mathbf{1 0 0 \% )}$ \\
\hline Viral Markers & Frequency (N) \\
\hline Hbv & $89(24.1 \%)$ \\
\hline Hbv+Hdv & $25(6.8 \%)$ \\
\hline Hcv & $244(66.1 \%)$ \\
\hline Hcv+Hbv & $11(3 \%)$ \\
\hline Total & $369(\mathbf{1 0 0 \% )}$ \\
\hline Child-Pugh Class & Frequency (N) \\
\hline Grade B & $100(27.1 \%)$ \\
\hline Grade C & $269(72.9 \%)$ \\
\hline Total & $369(\mathbf{1 0 0 \% )}$ \\
\hline Grades Of Hepatic Encephalopathy & Frequency (N) \\
\hline Grade-I & $0(0)$ \\
\hline Grade-II & $151(41 \%)$ \\
\hline Grade-III & $133(36 \%)$ \\
\hline Grade-IV & $85(23 \%)$ \\
\hline Total & $369(\mathbf{1 0 0 \% )}$ \\
\hline Hyponatremia & Frequency (N) \\
\hline No & $231(62.6 \%)$ \\
\hline Yes & $138(37.4 \%)$ \\
\hline Total & $369(\mathbf{1 0 0 \% )}$ \\
\hline & \\
\hline
\end{tabular}

Table-I. Descriptive statistics of age, duration of hepatic encephalopathy \& serum sodium level and frequency distribution of gender, viral markers, childPUGH class, grades of hepatic encephalopathy \& hyponatremia $(n=369)$.

\begin{tabular}{|c|c|c|c|c|}
\hline Varible & \multicolumn{3}{|c|}{ Hyponatremia } & \multirow{5}{*}{0.001} \\
\hline Age & No $(n=231)$ & Yes $(n=138)$ & Total & \\
\hline 35-53 Years & 129(34.95\%) & $86(23.31 \%)$ & $215(58.26 \%)$ & \\
\hline 54-70 Years & $102(27.65 \%)$ & $52(14.09 \%)$ & $154(41.74 \%)$ & \\
\hline Total & $231(62.6 \%)$ & $138(37.4 \%)$ & $369(100 \%)$ & \\
\hline Sex & $\mathrm{NO}(\mathrm{n}=231)$ & YES $(n=138)$ & TOTAL & \\
\hline Female & $111(30.1 \%)$ & $51(13.8 \%)$ & $162(43.9 \%)$ & סקחת \\
\hline Male & $120(32.5 \%)$ & $87(23.6 \%)$ & $207(56.1 \%)$ & 0.030 \\
\hline Total & $231(62.6 \%)$ & $138(37.4 \%)$ & $369(100 \%)$ & \\
\hline Viral Markers & $\mathrm{NO}(\mathrm{n}=231)$ & YES $(n=138)$ & TOTAL & \\
\hline HBV & $82(22.2 \%)$ & $7(1.9 \%)$ & $89(24.1 \%)$ & \\
\hline $\mathrm{HBV}+\mathrm{HDV}$ & $20(5.4 \%)$ & $5(1.4 \%)$ & $25(6.8 \%)$ & 0.001 \\
\hline $\mathrm{HCV}$ & 119(32.2\%) & $125(33.9 \%)$ & $244(66.1 \%)$ & 0.001 \\
\hline $\mathrm{HCV}+\mathrm{HBV}$ & $10(2.7 \%)$ & $1(0.3 \%)$ & $11(3 \%)$ & \\
\hline Total & $231(62.6 \%)$ & $138(37.4 \%)$ & $369(100 \%)$ & \\
\hline
\end{tabular}




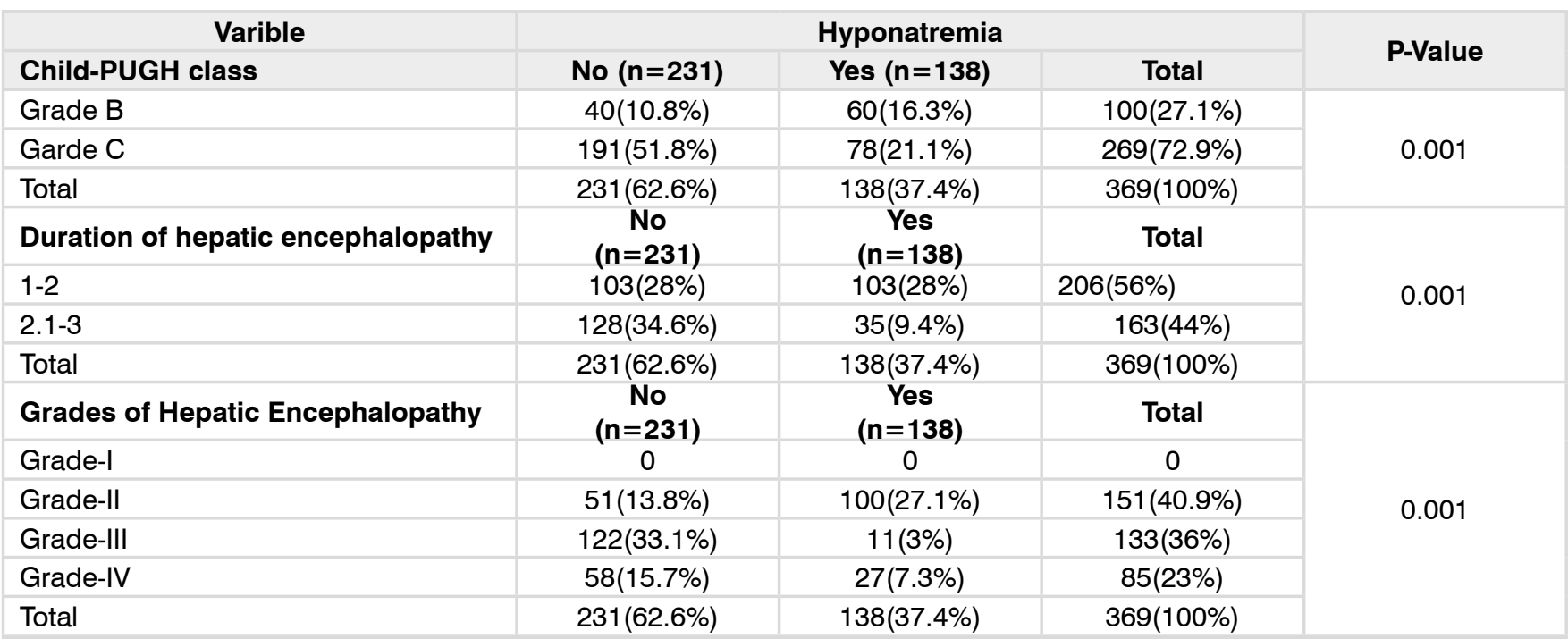

Table-III. Hyponatremia according to child-PUGH class, duration of hepatic encephalopathy \& grades of hepatic encephalopathy $(n=369)$

\section{DISCUSSION}

Hyponatremia in cirrhosis is clearly described as an independent mortality risk factor and is frequent in decompensated chronic liver disease. ${ }^{9}$ Model for End-stage Liver Disease (MELD) and serum sodium score, both estimate mortality in individuals with advanced cirrhosis on the waiting list of liver transplants. ${ }^{10}$ The combination of serum sodium with MELD (MELD-Na) estimated mortality in the waiting list than MELD score alone. This was particularly true in patients with a low overall MELD ratings. Patients with ascites complicated cirrhosis, due to low serum sodium, have a detrimental effect on their quality of life. A recent cross-sectional analysis of 523 participants with decompensated cirrhosis due to ascites showed a significant decrease in health-related quality of life (HRQL) in patients with hyponatremia and serum sodium below 130 meg / L. ${ }^{11}$ This effect was regardless of the extent of disease indicated by increased MELD score or liver failure. One interesting fact to be noted was, there was a striking affect on the HRQL, even in patients with minor hyponatremia, having serum sodium falling between $130 \mathrm{meq} / \mathrm{L}$ and $135 \mathrm{meq} / \mathrm{L}$. Recent data also suggest hyponatremia as a compact predictor of inferior HRQL, regardless of obvious cognitive impairment, and this may be strengthened following the elimination of diuretics in the subgroup of patients whose serum sodium counteracts this intervention. ${ }^{12}$
It is exhibited in several studies that the presence of hyponatremia has worsened hepatic encephalopathy. Hyponatremia with serum sodium less than or equal to $130 \mathrm{meq} / \mathrm{L}$ is one of the frequent predictive causes, along with record of serum creatinine, encephalopathy and bilirubin, for the development of overt hepatic encephalopathy in a 1 year study period. ${ }^{13}$ Hyponatremia was the best predictive factor with 10.5 HR (95 percent Cl: 5.4-20.3) for overt encephalopathy development in one year and was found to be associated with reduced rates of brain osmolyte, myo-inositol, promoting cerebral intracellular water changes and astrocyte inflammation in hepatic encephalopathy progression. Overt encephalopathy following trans-jugular portosystemic shunt (TIPS) deployment in patients with a serum sodium level of $135 \mathrm{mEq} / \mathrm{L} .{ }^{14}$ has also been shown to happen with higher frequency for variceal bleeding or refractory ascites.

The brain response to the onset of hyponatremia is unique. In a state of low extracellular osmolality, water flows down the osmotic gradient from the extracellular compartment into astrocytes, causing edema. Besides the outward flow of cations, such as potassium, there are a variety of organic chemicals, including myo-inositol, which can mitigate this effect by being transferred from the intracellular space to regulate the osmolality 
across compartments. ${ }^{15}$ Myo-inositol is also transferred from astrocytes in order to counteract the aggregation of glutamine that happens in cirrhosis when hyperammonemia is set. This depleted state in the setting of hyponatremia can actually lead to worsen hepatic encephalopathy and astrocyte swelling with oxidative stress. In addition, it has been shown that cirrhotic patients with hypo-osmolarity with and without hepatic encephalopathy have reduced myo-inositol levels in the brain, as seen on $1 \mathrm{H}-\mathrm{MR}$ spectroscopy. ${ }^{16}$

The frequency of hyponatremia and renal failure in cirrhotic patients admitted for skin and soft tissue infection was also shown to be greater than in matched cirrhotic controls without infection and correlated with higher 3-month mortality relative to patients without hyponatremia and renal failure (45\% vs. $19 \%) .{ }^{17}$

Patients with hyponatremia waiting for liver transplant were also shown to have worse consequences relative to normonatremic monitors. Using data derived from the Organ Procurement and Transplantation Network, Kim et al $^{10}$ established and evaluated a survival score that included serum sodium in the endliver disease model (MELD-Serum sodium was reported to independently predict serum sodium mortality between $125 \mathrm{mmol} / \mathrm{L}$ and $140 \mathrm{mmol}$ / L, with an HR of 1.05 per mmol decrease. The MELD-Na score was substantially greater in 7 per cent of patients who expired within 3 months of being identified for transplantation than MELD score alone. This finding indicated that there was a subgroup of patients benefiting from the achievement of sodium-based exception points that could speed up transplantation period. Hyponatremia has also recently been shown to forecast mortality in the first 90 days after being identified in a pediatric population for transplantation. ${ }^{18}$

In a study from Pakistan, more than half (51.6\%) patients with cirrhosis had serum sodium concentration below the normal range. ${ }^{4}$ The recent study reported $72 \%$ prevalence of hyponatremia in patients having liver cirrhosis, and hepatic encephalopathy was observed in $40 \%$ patients with serum sodium less than $130 \mathrm{mEq} / \mathrm{L},{ }^{19}$ mean prevalence of hyponatremia in cirrhotic patients with encephalopathy is $60 \%$. While khyalappa $\mathrm{R}$ et $\mathrm{al}^{3}$, showed hyponatremia was present in $34 \%$ of patients with encephalopathy. Almost $30 \%$ of patients with chronic liver disease usually die because of Porto systemic encephalopathy. ${ }^{20}$ In Khan et al study ${ }^{21}$ there was $72 \%$ prevalence rate of hyponatremia in liver cirrhosis of which $27.8 \%$ had mild, $41.7 \%$ moderate and $30.6 \%$ severe hyponatremia. Which was like Akbar et al study ${ }^{19}$ in the hyponatremia was identified in $72 \%$ (51 males and 21 females) patients. Study by Angeli $P$ et $\mathrm{al}^{22}$ had shown $50.6 \%$ mild, $27.8 \%$ moderate and $21.6 \%$ severe hyponatremia in cirrhotic patients. The frequency of hepato-renal syndrome was 11/72 (15\%) with severe hyponatremia, 7/72 $(9.7 \%)$ moderate hyponatremia, 3/72 (4\%) mild hyponatremia and 1/72 (1.3\%) with normal serum sodium concentration. Angeli $\mathrm{P}$ et $\mathrm{al}^{22}$ showed hepato-renal syndrome in $17 \%$ patients with severe hyponatremia, $10 \%$ moderate hyponatremia and $6 \%$ with normal sodium concentration which is quite closer to our study results.

Finally, our study showed that mortality rate is higher $(8.3 \%)$ in patients having moderate to severe hyponatremia. Hence it is important to note that vigilant monitoring and management of serum sodium concentration is effective tool in management of liver cirrhosis.

\section{CONCLUSION}

In conclusion, dilutional hyponatremia is a common finding in liver cirrhosis patients having encephalopathy leading to neurological impairment, hepatorenal syndrome, osteoporosis and high mortality. Therefore, early management of hyponatremia is key to prevent liver cirrhosis related complications.

\section{Copyright $@ 21$ Nov, 2020.}

\section{REFERENCE}

1. Nadeem M, Yousaf MA, Zakaria M, Hussain T, Ali N. The value of clinical signs in diagnosis of cirrhosis. Pak $\mathrm{J}$ Med Sci. 2005; 21:121-4. 
2. Almani A, Memon AS, Memon Al, Shah MI, Rahpoto $M Q$, Solangi $R$, et al. Cirrhosis of liver: Etiological factors, complications and prognosis. J Liaquat Uni Med Health Sci. 2008; 7:61-6.

3. Khyalappa R, Bardeskar A. Significance of hyponatremia in decompensated chronic liver diseases. Sch J App Med Sci. 2016; 4:606-08.

4. Qureshi MO, Khokhar N, Saleem A, Niazi TK. Correlation of hyponatremia with hepatic encephalopathy and severity of liver disease. J Coll Physicians Surg Pak. 2014; 24(2):135-37.

5. Gines P, Berl T, Bernardi M, Bichet DG, Haman G, Jimeneg $W$, et al. Hyponatremia in cirrhosis: from pathogenesis to treatment. Hepatol.1998; 28:851-64.

6. Shaikh S, Mal G, Khalid S, Baloch GH, Akbar Y. Frequency of hyponatraemia and its influence on liver cirrhosis-related complications. J Pak Med Assoc. 2010; 60(2):116-20.

7. Cardenas A, Gines P. Predicting mortality in cirrhosisserum sodium helps. N Engl J Med. 2008; 359:1060-6.

8. Bernardi M, Serena C, Santi L. Hyponatremia in patients with cirrhosis of the liver. $\mathrm{J}$ Clin Med. 2015; 4:85-101.

9. Biggins SW, Rodriguez HJ, Bacchetti P, Bass NM, Roberts JP, Terrault NA, et al. Serum sodium predicts mortality in patients listed for liver transplantation. Hepatology. 2005 Jan 1; 41(1):32-9.

10. Kim WR, Biggins SW, Kremers WK, Wiesner RH, Kamath PS, Benson JT, et al. Hyponatremia and mortality among patients on the liver-transplant waiting list. New Eng J Med. 2008 Sep 4; 359(10):1018-26.

11. Solà E, Watson H, Graupera I, Turón F, Barreto R, Rodríguez E, et al. Factors related to quality of life in patients with cirrhosis and ascites: Relevance of serum sodium concentration and leg edema. J Hepatol. 2012 Dec 31; 57(6):1199-206.

12. Ahluwalia V, Wade JB, Thacker L, Kraft KA, Sterling RK, Stravitz RT, et al. Differential impact of hyponatremia and hepatic encephalopathy on health-related quality of life and brain metabolite abnormalities in cirrhosis. J Hepatol. 2013 Sep 30; 59(3):467-73.
13. Guevara M, Baccaro ME, Torre A, Gómez-Ansón B, Ríos $\mathrm{J}$, Torres $\mathrm{F}$, et al. Hyponatremia is a risk factor of hepatic encephalopathy in patients with cirrhosis: A prospective study with time-dependent analysis. Am J Gastroenterol. 2009 Jun 1; 104(6):1382-9.

14. Riggio O, Angeloni S, Salvatori FM, De Santis A, Cerini $F$, Farcomeni $A$, et al. Incidence, natural history, and risk factors of hepatic encephalopathy after transjugular intrahepatic portosystemic shunt with polytetrafluoroethylene-covered stent grafts. $\mathrm{Am} \mathrm{J}$ Gastroenterol. 2008 Nov 1; 103(11):2738-46.

15. Córdoba J, García-Martinez R, Simón-Talero M. Hyponatremic and hepatic encephalopathies: similarities, differences and coexistence. Metabolic Brain Dis. 2010 Mar 1; 25(1):73-80.

16. Häussinger $D$, Schliess $F$. Pathogenetic mechanisms of hepatic encephalopathy. Gut. 2008 Aug 1; 57(8):1156.

17. Pugliese R, Fonseca EA, Porta G, Danesi V, Guimaraes T, Porta $A$, et al. Ascites and serum sodium are markers of increased waiting list mortality in children with chronic liver failure. Hepatol. 2014 May 1; 59(5):196471.

18. Yun BC, Kim W, Benson JT, Biggins SW, Therneau $\mathrm{TM}$, Kremers WK, et al. Impact of pre transplant hyponatremia on outcome following liver transplantation. Hepatol. 2009 May 1; 49(5):1610-5.

19. Akbar A, Jaffery MH, Memon MA, Arwani S, Memon HNA, Shah SZA. Liver cirrhosis; Frequency and severity of hyponatremia in patients. Professional Med J 2015;22(4):420-425.

20. Hayat SA, Shaikh N, Memon F. Identification of precipitating factors in hepatic encephalopathy patients at Liaquat University Hospital Jamshoro. World Appl Sci J. 2010; 8(6):661-66.

21. Khan AH, Hayat AS, Humaira M, Pathan GN, Akbar A. Hyponatremia; frequency and outcome in patients with liver cirrhosis. Professional Med J 2016;23(6):669672. DOI: $10.17957 / T P M J / 16.3337$

22. Angeli $\mathrm{P}$, Wong $\mathrm{F}$, Watson $\mathrm{H}$, Gines P. CAPPS investigators. hyponatremia in cirrhosis: Results of patient population servey. Hepatol. 2006; 44(6):153542. 


\begin{tabular}{|c|l|l|l|}
\hline \multicolumn{3}{|c}{ AUTHORSHIP AND CONTRIBUTION DECLARATION } \\
\hline Sr. \# & \multicolumn{1}{|c|}{ Author(s) Full Name } & \multicolumn{1}{c|}{ Contribution to the paper } & Author(s) Signature \\
\hline 1 & Tauqeer Shaikh & $\begin{array}{l}\text { Manuscript writing, Data } \\
\text { collection. } \\
\text { Manuscript writing, Proof } \\
\text { reading, Data collection. } \\
\text { Data collection, Data } \\
\text { analysis. } \\
\text { Manuscript writing. }\end{array}$ \\
\hline 3 & Hamid Ali Kalwar & Ghulam Mujtaba & Data analysis. \\
4 & Adeel Rahat & Kamaran Ali & Manuscript writing. \\
\hline 6 & Muhammad Babar &
\end{tabular}

